\title{
Mathematical Model for the Determination of Voltage and Current on Lossy Power Transmission Lines
}

\author{
M.O. Oke. \\ Department of Electrical \& Electronic Engineering, Ekiti State University, Ado-Ekiti, P.M.B. 5363, Ado-Ekiti, \\ Nigeria
}

\begin{abstract}
Energy is a basic necessity for the economic development of a nation. There are different forms of energy, but the most important form is the electrical energy. A modern and civilized society is so much dependent on the use of electrical energy. Electrical energy is transmitted by means of transmission lines which deliver bulk power from generating stations to load centers. The industrial development of any nation depends majorly upon the reliability of its interconnected electric power system. Availability of electric energy has been the most powerful vehicle for facilitating economic, industrial and social developments of any nation. When an electric power is generated in sufficient quantities, it needs to be transmitted in bulk to load centers and then distributed to individual consumers in proper form and quality at the lowest possible ecological and economic price. This electric power is transmitted by means of transmission lines. In this paper, we developed mathematical models for the determination of voltage and current on lossy electric power transmission lines. We derived relations which the voltage and current must satisfy on a uniform transmission line. The models contain the primary constants or parameters of the transmission line which include the series resistance $(R)$, the shunt conductance $(G)$, the inductance $(L)$ and the capacitance $(C)$. Values of these constants are specified per unit length.
\end{abstract}

Keywords: Transmission line equations, Mathematical model, Lossy transmission, Leakages in transmission line, Transmission parameters.

\section{Introduction}

The social structures and the industrial development of any country depend primarily upon low cost and uninterrupted supply of electrical energy, Mehta et al. (2008). The process of modernization, increase in productivity, agriculture and industry basically depend upon the adequate supply of electrical energy, Gupta (2008).

Generation of electrical energy is the conversion of energy available in different forms in nature to electrical energy. The ever increasing use of electrical energy for industrial, domestic and commercial purposes necessitated the bulk production of electrical energy. This bulk production is achieved with the help of suitable power production stations which are generally referred to as electric power generating stations or electric power plants. A generating station usually employs a prime mover coupled with an alternator to produce electric power.

Electrical energy is generated at power stations which are usually situated far away from load centers. Hence an extensive network of conductors between the power stations and the consumers is required. This network of conductors may be divided into two main components, called the transmission system and the distribution system. The transmission system is to deliver bulk power from power stations to load centers and large industrial consumers while the distribution system is to deliver power from substations to various consumers.

Electrical energy must be transmitted and distributed to the point of use as soon as it is needed. Transmission lines and other materials are needed to achieve this purpose. Transmission lines are materials or media that are used to transmit electric energy and signals from one point to another, specifically from a source to a load. They can be regarded as a set of conductors being run from one place to another and supported on transmission towers. This involves connections between an electric generating plant and a substation which is several hundred kilometers away. The transmission and distribution stages are very important to electric power system because without these stages the generated power cannot get to the load centers not to talk of getting to the final consumers, Mehta et al. (2008), Wadhwa (2009) and Atandare (2007).

\section{Motivation for the Study}

A lot of research work had been carried out by scientists and engineers on the generation of power, reliability of transmission systems and reduction of losses on transmission lines: Bamigbola et al. (2009) considered the characterization of optimal control model of electric power generating systems using two control variables, Aderinto (2010) developed a mathematical model for electric power generating system using the 
optimal control approach with one control variable, Okafor et al. (2009) assessed the reliability of transmission systems in Nigeria by using the general reliability function and calculating the reliability indices for six 330KV transmission lines in Nigeria. Bagriyanik et al. (2003) used a fuzzy multi-objective optimization and genetic algorithm-based method to find optimum power system operating conditions. In addition to active power losses, series reactive power losses of transmission system are also considered as one of the multiple objectives. Onohaebi et al. (2010) considered the relationship of the effect of distance and loadings on power losses using the existing 28 bus, 330KV Nigerian transmission network as a case study in his empirical modeling of power losses as a function of line loadings and lengths in the Nigeria $330 \mathrm{KV}$ transmission lines, to mention a few. The mathematical models for the determination of voltages and currents on lossy electric power transmission lines has not been work upon by any of these researchers hence the need for this work. In this paper, we present the mathematical models for the determination of voltage and current on lossy electric power transmission lines in form of second order partial differential equations.

The relation which the voltage and current must satisfy on a uniform transmission line was derived. We constructed a circuit model for an incremental length of line and write two circuit equations which we now used to obtain our transmission line equations. A real transmission line will have some series resistance associated with the losses in the conductor, Williams et al. (2006). There may also be some shunt conductance, if the insulating material holding two conductors has some leakage current. Therefore, resistance and conductance are responsible for power loss in transmission, Williams et al. (2006). So they are very important when transmission efficiency and economy are to be evaluated. To this effect, we formulate a model for a lossy transmission line where the effect of the series resistance $(\mathrm{R})$ and shunt conductance $(\mathrm{G})$ are taken care of in the transmission line.

\section{Model Formulation.}

In this work, we are interested in determining the extent to which the output voltage and current differs from their input values as the length of the transmission line approaches a very small value. To this end, we consider an equivalent circuit of a transmission line of length $\Delta x$ containing resistance $\mathrm{R} \Delta x$, capacitance $\mathrm{C} \Delta x$, inductance $\mathrm{L} \Delta x$ and conductance $\mathrm{G}^{\Delta x}$ as shown in the figure below:

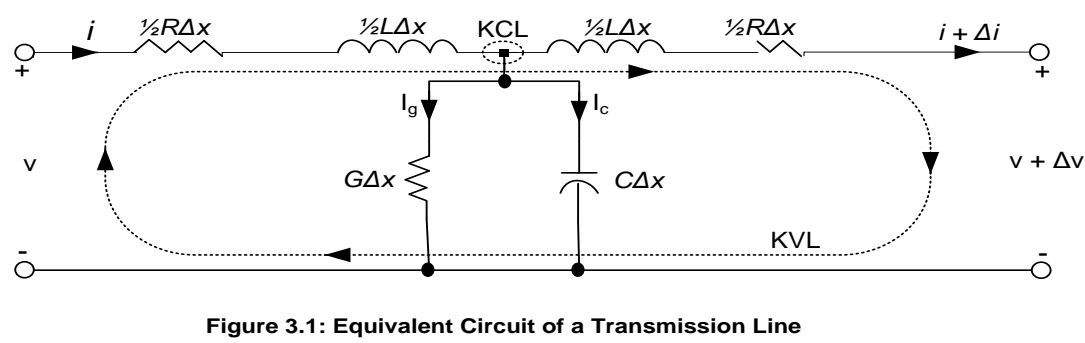

The figure above is a symmetrical network; we therefore divide the series elements in half. Kirchhoff's Voltage Law (KVL) we have

$v=\frac{1}{2} R i \Delta x+\frac{1}{2} L \frac{\partial i}{\partial t} \Delta x+\frac{1}{2} L\left[\frac{\partial i}{\partial t}+\frac{\partial \Delta i}{\partial t}\right] \Delta x+\frac{1}{2} R[i+\Delta i] \Delta x+v+\Delta v$

Using the

Dividing through equation (3.1) by $\Delta x$ and simplifying, we have

$\frac{\partial v}{\partial x}=-\left[R i+L \frac{\partial i}{\partial t}+\left(\frac{L}{2} \frac{\partial^{2} i}{\partial t \partial x}+\frac{R}{2} \frac{\partial i}{\partial x}\right) \Delta x\right]$

Taking limit as $\Delta x \rightarrow 0$, we have

$\frac{\partial v}{\partial x}=-\left[R i+L \frac{\partial i}{\partial t}\right]$

Applying the Kirchhoff's Current Law (KCL) on the equivalent circuit of the transmission line, we have

$i=i_{g}+i_{c}+i+\Delta i$

i.e

$i=G\left[v+\frac{\Delta v}{2}\right] \Delta x+C \frac{\partial}{\partial t}\left[v+\frac{\Delta v}{2}\right] \Delta x+i+\Delta i$

Dividing through equation (3.5) by $\Delta x$ and simplifying, we have

$\frac{\partial i}{\partial x}=-\left[G v+C \frac{\partial v}{\partial t}+\left(\frac{C}{2} \frac{\partial^{2} v}{\partial t \partial x}+\frac{G}{2} \frac{\partial v}{\partial x}\right) \Delta x\right]$

Taking limit as $\Delta x \rightarrow 0$, we have 
$\frac{\partial i}{\partial x}=-\left[G v+C \frac{\partial v}{\partial t}\right]$

The differential equations in (3.3) and (3.7) above describe the evolution of current and voltage in a lossy transmission line.

Differentiating equation (3.3) with respect to $\mathrm{x}$ we have

$\frac{\partial^{2} v}{\partial x^{2}}=-L \frac{\partial^{2} i}{\partial x \partial t}-R \frac{\partial i}{\partial x}$

and differentiating equation (3.7) with respect to $t$, we have

$\frac{\partial^{2} i}{\partial t \partial x}=-C \frac{\partial^{2} v}{\partial t^{2}}-G \frac{\partial v}{\partial t}$

Substituting (3.7) and (3.9) in (3.8), we have

$\frac{\partial^{2} v}{\partial x^{2}}=C L \frac{\partial^{2} v}{\partial t^{2}}+L G \frac{\partial v}{\partial t}+R\left[G v+C \frac{\partial v}{\partial t}\right]$

Differentiating equation (3.3) with respect to $t$ we have

$\frac{\partial^{2} v}{\partial t \partial x}=-L \frac{\partial^{2} \tilde{i}}{\partial t^{2}}-R \frac{\partial i}{\partial t}$

and differentiating equation (3.7) with respect to $\mathrm{x}$, we have

$\frac{\partial^{2} i}{\partial x^{2}}=-C \frac{\partial^{2} v}{\partial x \partial t}-G \frac{\partial v}{\partial x}$

Substituting (3.3) and (3.11) in (3.12), we have

$\frac{\partial^{x_{i}}}{\partial x^{2}}=C L \frac{\partial^{x_{i}}}{\partial t^{2}}+C R \frac{\partial i}{\partial t}+G\left[R i+L \frac{\partial i}{\partial t}\right]$

Equations (3.10) and (3.13) are hyperbolic partial differential equations which describes the voltage and current along power transmission lines.

\section{Conclusion}

We have formulated first order partial differential equations which gives the evolution of voltage and current on transmission lines by making use of the Kirchhoff's circuit laws as a working tool. Second order partial differential equations which describe the voltage and current along power transmission lines were also derived in the paper.

\section{References}

[1]. Aderinto, Y.O. An Optimal Control Model of the Electric Power Generating System; Unpublished Ph.D. Thesis, Department of Mathematics, University of Ilorin, Nigeria, 2010.

[2]. Atandare, D.L. Nigerian's Epileptic power supply - the way out; Prof. E.K. Obiakor Lecture Series 8, The Federal Polytechnic, Ado-Ekiti, 2007.

[3]. Bagriyanik, F.G., Aygne, Z.E. and Bagriyanik, M. Power Loss Minimization Using Fuzzy Multi-objective Formulation and Genetic Algorithm, Presented at IEEE Power Tech Conference, June $23^{\text {rd }} 26^{\text {th }}$, Bologna, Italy, 2003.

[4]. Bamigbola, O.M. and Aderinto, Y.O. On the Characterization of Optimal Control Model of Electric power Generating Systems; International Journal of Physical Sciences, Volume4, Number 1, 2009.

[5]. Gupta, J.B. A Course in Power System; S.K. Kataria \& Sons, Publisher of Engineering and Computer books, New Delhi, 2008.

[6]. Mehta, V.K and Mehta, R. Principles of Power Systems; S. Chand \& Company Ltd, New Delhi, 2008.

[7]. Okafor, C.E. and Adebanji, B. An Assessment of Transmission System Reliability in Nigeria; Journal of Research in Engineering (JRENG), Vol. 6, 2009, 21-34.

[8]. Onohaebi, O.S. and Odiase, O.F. Empirical Modeling of Power Losses as a Function of Line Loadings and Lengths in the Nigerian 330KV Transmission Lines; International Journal of Academic Research, 2010, 47-53.

[9]. Wadhwa, C.L. Electrical Power Systems; New Age International (P) Limited, Publishers, New Delhi, 2009.

[10]. Williams, H.H. Jr and John, A.B. Engineering Electromagnetics; McGraw-Hill Company Ltd., New York, 2006. 